\title{
The effect of a new specific $\alpha$-amylase inhibitor on post-prandial glucose and insulin excursions in normal subjects and Type 2 (non-insulin-dependent) diabetic patients
}

\author{
H. G. Eichler ${ }^{1}$, A. Korn ${ }^{1}$, S. Gasic ${ }^{1}$, W. Pirson ${ }^{2}$ and J. Businger ${ }^{2}$ \\ ${ }^{1}$ Department of Clinical Pharmacology, I. Medizinische Universitätsklinik, Vienna, Austria and ${ }^{2}$ F. Hoffmann-La Roche, Basle, Switzerland
}

\begin{abstract}
Summary. Trestatin (Ro 9-0154), a new specific $\alpha$-amylase inhibitor of microbial origin, was tested in six normal subjects and seven Type 2 (non-insulin-dependent) diabetic patients. In normal subjects the maximal increases in blood glucose following a $115 \mathrm{~g}$ starch meal were $2.19 \pm 0.57 \mathrm{mmol} / 1$ (mean $\pm \mathrm{SEM}$ ) with placebo, but $1.32 \pm 0.39 \mathrm{mmol} / 1$ with $10 \mathrm{mg}, 1.06 \pm 0.26 \mathrm{mmol} / \mathrm{l}$ with $20 \mathrm{mg}, 0.43 \pm 0.07 \mathrm{mmol} / 1$ with $50 \mathrm{mg}(p<0.05)$ and $0.26 \pm 0.14 \mathrm{mmol} / 1$ with $100 \mathrm{mg}(p<0.05)$ Trestatin. The corresponding increases in plasma insulin were $116.5 \pm 19.6 \mathrm{mU} / 1 ; 74.8 \pm 17.5 \mathrm{mU} / 1 ; 50.7 \pm 8.3 \mathrm{mU} / 1$; $28.7 \pm 6.9 \mathrm{mU} / 1(p<0.05)$ and $16.5 \pm 3.2 \mathrm{mU} / 1(p<0.05)$. In the diabetic patients the maximal increases in blood glucose following a $50 \mathrm{~g}$ starch meal were $6.09 \pm 0.02 \mathrm{mmol} / 1$ with
\end{abstract}

placebo, but $3.17 \pm 0.59 \mathrm{mmol} / 1(p<0.05)$ with $10 \mathrm{mg}$ and $1.69 \pm 0.41 \mathrm{mmol} / 1(p<0.05)$ with $30 \mathrm{mg}$ Trestatin. The corresponding insulin increases were: $58.8 \pm 12.7 \mathrm{mU} / \mathrm{l}, 31.5 \pm$ $9.7 \mathrm{mU} / 1(p<0.05)$ and $23.4 \pm 4.8 \mathrm{mU} / 1(p<0.05)$. Trestatin fully retained this pharmacological activity during treatment for 4 weeks in the diabetic patients. Trestatin did not influence glucose and insulin profiles after oral glucose and sucrose. These results are consistent with a specific inhibition of $\alpha$-amylase in man.

Key words: Trestatin, Ro 9-0154, Type 2 diabetes, $\alpha$-amylase inhibitor, starch digestion, starch meal, blood glucose, plasma insulin.
Delay of carbohydrate digestion by inhibitors of digestive enzymes in the intestine may represent a new approach to the treatment of diabetes as it seems to provide a means of reducing post-prandial hyperglycaemia. Several $\alpha$-amylase inhibitors and inhibitors of other $\alpha$-glucosidases (e.g. sucrase, maltase) have been investigated for this purpose [1] and some preliminary results of clinical trials with acarbose, an $\alpha$-glucosidase inhibitor, have been presented [2].

Trestatin (Ro 9-0154), a new specific inhibitor of $\alpha$ amylase, is a partially purified mixture of complex oligosaccharides produced by Streptomyces dimorphogenes. It consists of three main components (Trestatin $\mathrm{A}, \mathrm{B}, \mathrm{C}$ ) with trehalose as characteristic common constituent. Inactivation of $\alpha$-amylase by Trestatin occurs through rapid formation of a stable enzyme inhibitor complex. In rats and dogs Trestatin at oral doses of $0.1-1.0 \mathrm{mg} / \mathrm{kg}$ reduces the increase in blood glucose and insulin after a starch load.

The aim of this study was to assess the effect of Trestatin in normal subjects and Type 2 (non-insulindependent) diabetic patients after starch meals. To demonstrate the specificity of Trestatin, tests with oral sucrose and glucose loads were included in the studies on normal subjects.

\section{Subjects and methods}

All experimental protocols were approved by our Human Investigation Ethical Committee. Informed consent was obtained from all subjects. All experiments were single blind. Subjects with impaired liver and kidney function and those who had undergone gastric resection or vagotomy were excluded from the study. All subjects were asked to report side effects.

Trestatin was used as an aqueous drop solution. It was dripped on slices of bread or mixed with mashed potato to ensure optimal interaction with amylase during digestion.

Routine clinical and laboratory examinations were performed before and after the trials in all subjects: bilirubin, alkaline phosphatase, glutamic oxalacetic transaminase, glutamic pyruvic transaminase, $\gamma$ glutamyl transpeptidase, lactate dehydrogenase, cholesterol, triglycerides, blood urea nitrogen, creatinine, uric acid, erythrocyte sedimentation rate and full blood count.

\section{Normal subject studies}

Six normal subjects (five males, one female); aged $23 \pm 1$ years (mean \pm SEM); $105 \pm 3 \%$ desirable weight [3] received 10, 20, 50 and $100 \mathrm{mg}$ Trestatin, thrice daily on consecutive days. A placebo was administered for 2 days before the trial and for 1 day afterwards. The diet was standardized to contain $115 \mathrm{~g}$ starch with breakfast (white bread), and $67.5 \mathrm{~g}$ starch with lunch and dinner (mashed potatoes), thus amounting to $250 \mathrm{~g}$ starch/day. Fat intake was limited to $80 \mathrm{~g}$ / day. Blood samples for blood glucose and plasma insulin were obtained before and half hourly (up to $2 \mathrm{~h}$ ) after breakfast and lunch. 

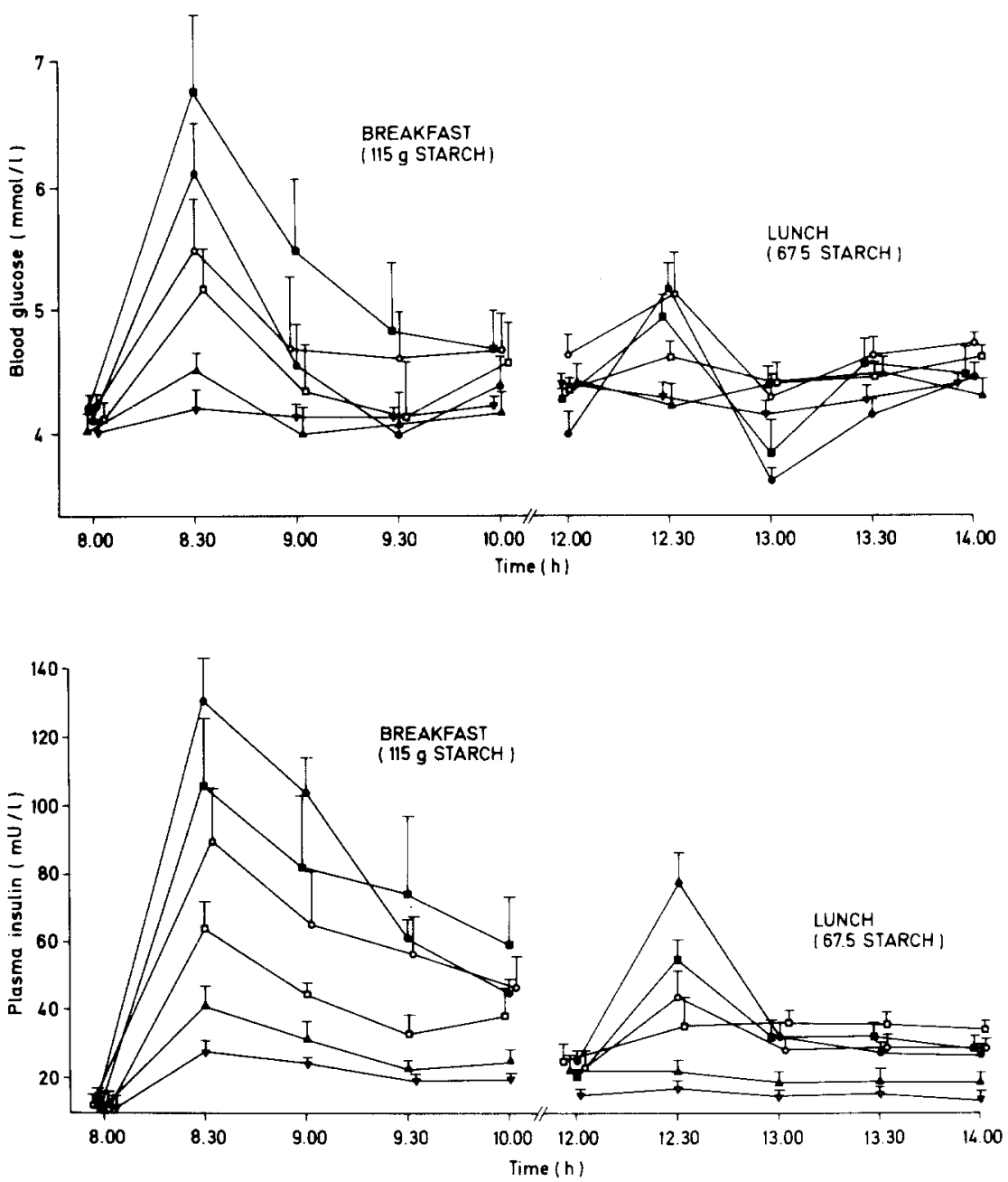

Fig. 1. Effect of increasing doses of Trestatin on mean blood glucose (top panel) and mean plasma insulin profiles (bottom panel) after starch meals in six normal subjects (mean \pm SEM represented by vertical bars). placebo 1 (pre-treatment); placebo 2 (post-treatment) $\bigcirc-\bigcirc 10 \mathrm{mg} ; \square-\square 20 \mathrm{mg}$; $\triangle \longrightarrow$ - $50 \mathrm{mg} ; \mathbf{\nabla} \longrightarrow \mathbf{\nabla} 100 \mathrm{mg}$

Six further normal subjects (all male; aged $24 \pm 1$ years; $106 \pm 2 \%$ desirable weight) received $75 \mathrm{~g}$ of glucose and sucrose (in $400 \mathrm{ml}$ water) after an overnight fast, with either placebo or $50 \mathrm{mg}$ Trestatin added (cross-over design).

\section{Patient studies}

Acute studies: Seven Type 2 diabetic patients (two males, five females; aged $62 \pm 5$ years; $136 \pm 11 \%$ desirable weight), who did not require oral anti-diabetic therapy, were admitted to hospital 4 days before the study and received a constant diabetic diet (total energy content: $1500-2000$ calories/day of which approximately $45 \%$ carbohydrates, $25 \%$ protein, $30 \%$ fat). Patients were divided into two groups: group A $(n=4)$ received placebo, 10,20 and $30 \mathrm{mg}$ Trestatin thrice daily on consecutive days; group B ( $n=3)$ received placebo, 10,30 and $50 \mathrm{mg}$ Trestatin thrice daily also on consecutive days. Blood glucose and plasma insulin profiles ( $30 \mathrm{~min}$ intervals) were performed for $3 \mathrm{~h}$ after a $50 \mathrm{~g}$ starch breakfast ( $100 \mathrm{~g}$ white bread). Starch content of the other meals was tailored to the patients' dietary requirements and kept constant over the trial period.

Short-term treatment: Six patients agreed to continue Trestatin for 4 weeks. They were advised to maintain their usual diet and to add Trestatin to all starch-containing foods of the three main meals (i. e. to drip it on bread, mix it with noodles, mashed potato, etc.). Dosage was either 20 or $30 \mathrm{mg}$, thrice daily, depending on the individual results of the previous (dose range) study. Blood glucose and plasma insulin profiles $(30 \mathrm{~min}$ intervals) were performed for $2 \mathrm{~h}$ after $50 \mathrm{~g}$ starch $(100 \mathrm{~g}$ white bread) at weekly intervals.

\section{Laboratory investigations}

Glucose was analyzed in whole blood using the hexokinase reaction (reagent: Boehringer-Mannheim, FRG; Cobas Bio System, Roche, Basle, Switzerland). Plasma insulin was measured by a commercially available radioimmunoassay kit (International CIS, St.Quentin France). Routine enzyme and substrate determinations were carried out using standard laboratory procedures (reagents: BoehringerMannheim, and Merck Darmstadt, FRG; equipment: Cobas Bio, Roche, Basle, Switzerland; SMA II Technicon, Tarrytown, New York, USA).

\section{Calculations and statistical analysis}

The area under the curve was calculated for post-prandial glucose and insulin rises. These data were analyzed by two way analysis of variance followed by Tukey's test. A $p$ value $<0.05$ in the Tukey's test was considered significant. In the normal subject study, the mean value of the two pre-treatment placebo days was used as a control.

\section{Results}

\section{Normal subject studies}

Blood glucose and plasma insulin profiles following breakfast and lunch are shown in Figure 1. Trestatin administration led to a dose-dependent reduction of the 

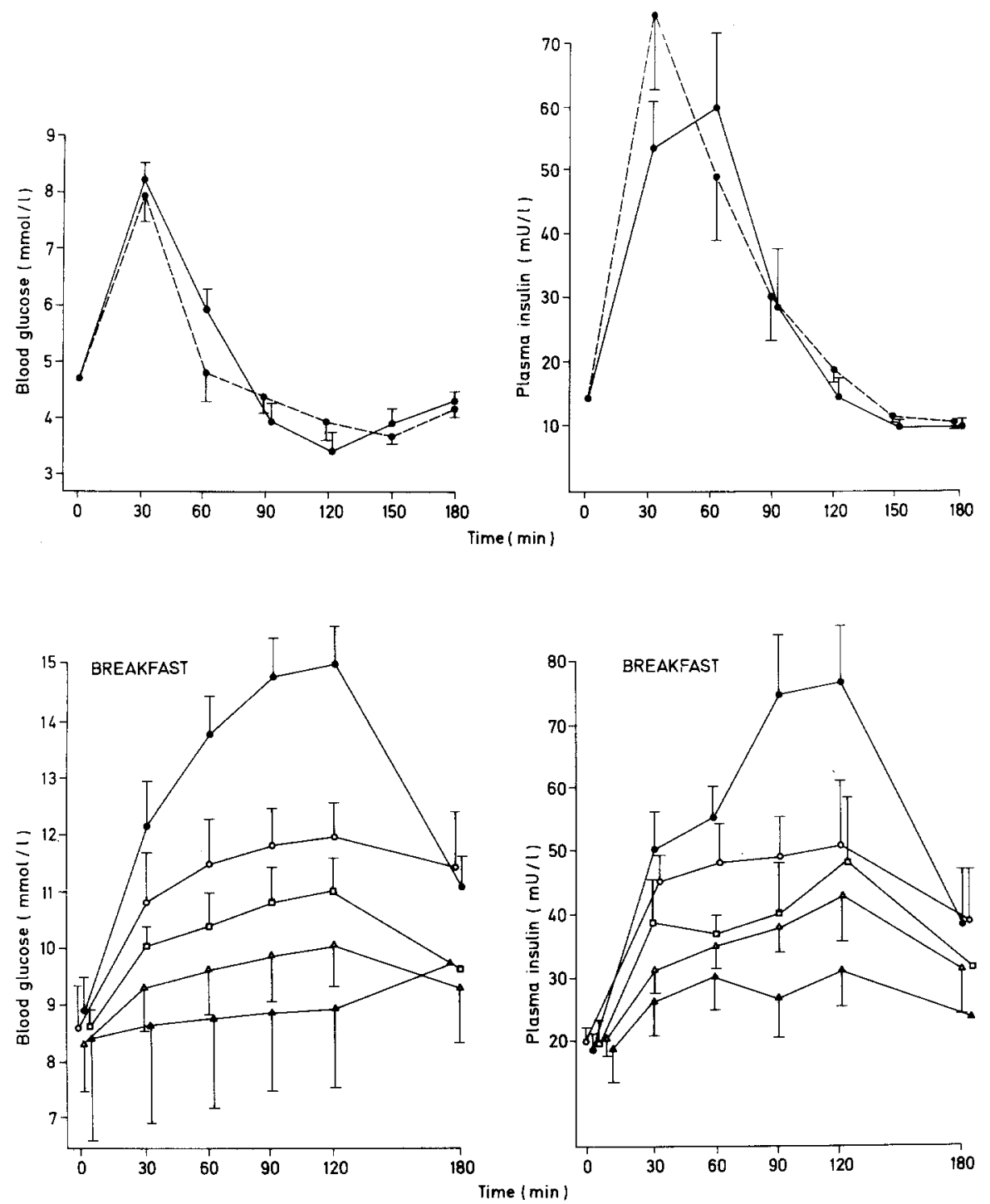

Fig. 2. Mean blood glucose and mean plasma insulin increases after $75 \mathrm{~g}$ sucrose with placebo (- - ) and $50 \mathrm{mg}$ Trestatin $(\mathbf{0}--\mathbf{0})$ in six normal subjects (SEM represented by vertical bars)

Fig. 3. Effect of increasing doses of Trestatin on mean blood glucose (left panel) and mean plasma insulin profiles (right panel) after $50 \mathrm{~g}$ starch in two groups (A: $n=4 \mathrm{~B}: n=3$ ) of Type 2 diabetic patients. SEM is represented by vertical bars. $\longrightarrow$ placebo (groups A+B); $\mathrm{O}-\mathrm{O} 10 \mathrm{mg}$ (groups A+B); $\square-\square 20 \mathrm{mg}$ (group A); $\triangle \longrightarrow \triangle 30 \mathrm{mg}$ (groups A+B); — $50 \mathrm{mg}$ (group B)

rise in blood glucose and plasma insulin after breakfast and lunch. Statistically significant effects were reached with 50 and $100 \mathrm{mg}$ Trestatin at breakfast (for glucose and insulin) and at lunch (for insulin only) ( $p<0.05$ versus placebo). The $100 \mathrm{mg}$ dose nearly abolished the post-prandial glucose and insulin increase. Values from the control day after the trial (placebo 2, Fig.1) were similar to the pre-trial profile.

Trestatin did not influence glucose and insulin profiles after oral glucose (data not shown) or sucrose (Fig. 2).

Routine biochemical and haematological measurements were all within the normal range at the end of the trials. Five of the six volunteers reported abdominal discomfort, flatulence and diarrhoea, mostly with the 50 and $100 \mathrm{mg}$ doses.

\section{Patient studies}

Acute studies: In the diabetic patients, Trestatin at doses of $10-50 \mathrm{mg}$ reduced the increase of glucose and insulin after breakfast in a dose-dependent manner (Fig. 3). The effects of $10 \mathrm{mg}$ and $30 \mathrm{mg}$ Trestatin were significant for glucose and insulin ( $p<0.05$ versus placebo). No statistical analysis was calculated for the 20 and $50 \mathrm{mg}$ doses because of limited numbers. The $50 \mathrm{mg}$ dose nearly abolished the post-prandial rise of blood glucose.

All patients reported flatulence on the day when the highest dose was given ( 30 or $50 \mathrm{mg}$ ) and one patient reported diarrhoea.

Short-term study: Six patients agreed to continue Trestatin for 4 weeks, but one patient dropped out during the first week. In the remaining five, the reduction of the post-prandial rise of glucose and insulin after the standard starch meal remained constant throughout the 4-week period (Table 1). Fasting blood glucose and insulin values were unchanged (data not shown). Routine laboratory measurements remained in the normal range. Flatulence was reported by all five patients, three of whom reported it as uncomfortable. 
Table 1. Increments above baseline (area under the curve) up to $2 \mathrm{~h}$ for blood glucose and plasma insulin in five Type 2 diabetic patients after 50 -g starch meals during 4 weeks of treament with Trestatin ( 20 or $30 \mathrm{mg}$ thrice daily)

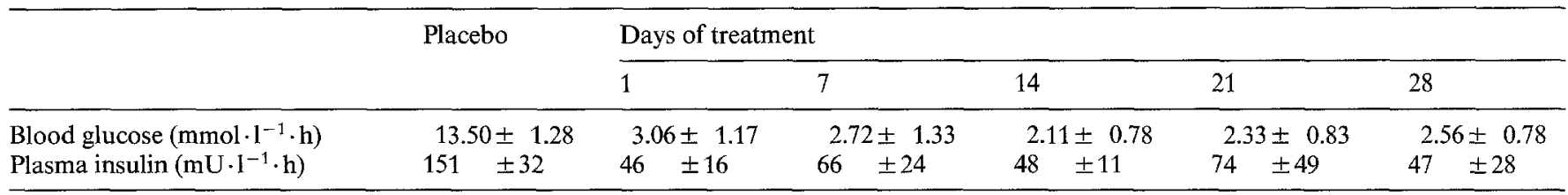

Results are expressed as mean \pm SEM

\section{Discussion}

This study in normal subjects and Type 2 diabetic patients demonstrates the inhibitory effect of Trestatin on the increase in blood glucose and plasma insulin after starch meals. In the diabetic patients, this was significant at a dose of $10 \mathrm{mg}$ per meal. The effect of Trestatin was dose-dependent over the dose range studied, but due to the non-randomized study design (increasing doses on consecutive days) a carry-over effect cannot be excluded. Nevertheless, the effect of Trestatin was reversible as demonstrated by the control values after the trial in the volunteers.

The specificity of Trestatin in inhibiting starch digestion was shown by the lack of effect after ingestion of sucrose or glucose with the high dose of Trestatin $(50 \mathrm{mg})$. This is in accordance with its specific inhibition of $\alpha$-amylase, and confirms previous results in rats [4].

Flatulence, and to a lesser degree diarrhoea, were the only side effects reported. The prevalence and severeness of flatulence did not increase during the 4-week trial. It could possibly be reduced by using a lower dose without loss of efficacy.

In conclusion, Trestatin has been shown to be a potent inhibitor of starch digestion in man. This effect apparently is brought about by a specific inhibition of $\alpha$ amylase. Further studies are warranted to assess the long-term effects and safety of this drug and to compare it with other $\alpha$-glucosidase inhibitors. The role of these agents in the treatment of diabetes remains to be established.

Acknowledgements. We thank H. Lentner and V. Pieber for excellent technical assistance. We are grateful to Professor F.Gabl and the Institute of Clinical Chemistry for glucose and routine enzyme and substrate determinations.

\section{References}

1. Truscheit E, Frommer W, Junge B, Müller L, Schmidt DD, Wigender W (1981) Chemie und Biochemie mikrobieller Alpha-Glucosidase-Inhibitoren. Angew Chem 93: 738-755

2. Creutzfeldt W (ed) (1982) First International Symposium on Acarbose, Montreux 1981. Excerpta Medica, Amsterdam Oxford Princeton

3. Diem K, Lentner C (eds) (1971) Scientific tables. Ciba-Geigy Basel, p 712

4. Pirson W, Buchschacher P (1981) Pharmacological properties of Trestatin, a new alpha-amylase inhibitor (Ro 9-0154). Diabetologia 21: 315 (Abstract)

Received: 7 December 1982

and in revised form: 6 February 1984

Dr. H.G. Eichler

Department of Clinical Pharmacology

I. Medizinische Universitätsklinik

Lazarettgasse 14

A-1090 Vienna

Austria 